http://jmscr.igmpublication.org/home/ ISSN (e)-2347-176x ISSN (p) 2455-0450

crossref DOI: https://dx.doi.org/10.18535/jmscr/v8i11.14

\title{
A Case of Adult Onset Still's Disease Presented with Macrophage Activation Syndrome and Secondary Haemophagocytic lymphohistiocytosis
}

\author{
Authors \\ Dr G. Sucharitha ${ }^{1}$, Dr S. Sreenivas MD $^{2}$ \\ ${ }^{1}$ General Medicine Postgraduate, Andhra Medical College, Visakhapatnam \\ ${ }^{2}$ Professor, Department of General Medicine, Andhra Medical College, Visakhapatnam
}

\section{Introduction}

Haemophagocytic lymphohistiocytic syndrome is ahyper inflammatory syndrome due to highly stimulated but ineffective immuneprocess. Based on the etiology it is of two types Primary (Genetic) and Secondary or Acquired (infections, autoimmune and malignant diseases)

Adult onset Still's disease is an autoimmune inflammatory disease most often seen in young adults of age between 16 to 35 years but rarely can present above 35 years also. It effects women slightly more than men. Adult onset Still's disease is a clinical diagnosis based on recognition and exclusion of other diseases. It generally presents with fever, arthralgia, rash and Splenomegaly. Here we report a $41 \mathrm{yr}$ old female patient with features of secondary HLH in whom Adult onset Still's disease was diagnosed as the cause for secondary HLH.

\section{Case Study}

A 41-year-old female patient with nocomorbities was referred to our hospital with history of fever, arthralgia, myalgia since 2 months and history of altered sensoriumsince 2 days. Feverintermittent, high grade associated with chills, arthralgia, myalgia not associated with sweating and subsiding with antipyretics. No history of cough, headache, blurring of visionor seizures. No history of rash, raynaud's phenomenon, oral or genital ulcers. Arthralgia involving large joints mostly knees and ankles.

Past History: Patient had history of recurrent episodes of on and off fever associated with myalgia, arthralgia since 10 years which was relieved spontaneously and sometimes with simple medication.

On Examination at the time of presentation: Patient was in altered sensorium. She was pale and had bilateral pitting type of pedal edema .Her vitals:

Temp:- $101^{\circ} \mathrm{F}$, Pulse Rate: 130beats /min, Blood pressure:90/60 mm Hg.

Central Nervous System: Patient was in altered sensorium GCS: E4V1M4.

Pupils: Normal size reacting to light.

Tone was normal and plantar reflex was flexor on both sides .No neck stiffness

Cardiovascular System: No abnormality detected.

Respiratory System: No abnormality detected.

Gastrointestinal System: Hepatosplenomegaly was present

Investigations: Her initial reports showed haemoglobin9 $\mathrm{gm} / \mathrm{dl}$, total count $12,400 \mathrm{cells} / \mathrm{mm}$ 
3 with $91 \%$ neutrophils and platelets of 1.49 lakhs $/ \mathrm{mm} 3$.

She was investigated, her haemoglobin, platelet count were going down day by day but there was no history of any bleeding manifestations.

\begin{tabular}{|c|c|c|c|}
\hline Haemoglobin & $9 \mathrm{gm} / \mathrm{dl}$ & $7.5 \mathrm{gm} / \mathrm{dl}$ & $6.2 \mathrm{gm} / \mathrm{dl}$ \\
Total count & $\begin{array}{c}12,400 \\
\text { cells/mm3 }\end{array}$ & 7,600 cells $/ \mathrm{mm}$ & 3,900 cells $/ \mathrm{mm}$ \\
Differential & & 3 & 3 \\
count : & & & \\
Polymorphs & $91 \%$ & $80 \%$ & $85 \%$ \\
Lymphocytes & $7 \%$ & $15 \%$ & $10 \%$ \\
Eosinophils & $2 \%$ & $2 \%$ & $3 \%$ \\
\hline Platelets & $1.491 \mathrm{akhs} /$ & 94,000 & 60,000 \\
& $\mathrm{~mm} 3$ & cells $/ \mathrm{mm} 3$ & cells $/ \mathrm{mm} 3$ \\
\hline PCV & $29.2 \%$ & $25 \%$ & $18.5 \%$ \\
\hline ESR & $20 \mathrm{~mm} / \mathrm{hr}$ & $35 \mathrm{~mm} / \mathrm{hr}$ & $52 \mathrm{~mm} / \mathrm{hr}$ \\
\hline
\end{tabular}

Peripheral smear:- Microcytic Hypochromicand polychromatophilic and few macrocytic red blood cells and Neutrophilic leukocytosis.

Serum electrolytes (Sodium, potassium, calcium and magnesium ) were normal.

Tests for Malaria, Dengue, Chikungunya, Typhoidand scrub typhus were negative.

Her blood cultures and urine cultures were sterile.

Chest x Ray was normal.

Ultrasound abdomen showed massive hepatosplenomegaly.

CSF Analysis: TC- O, DC -O, Protein $-83 \mathrm{mg} / \mathrm{dl}$, Sugar: $68 \mathrm{mg} / \mathrm{dl}$. Meningitis Panel was done for bacteria, viruses and fungi were Negative. CSF analysis for CBNAAT is negative and no acid fast bacilli detected.

Screening for HIV, HbsAg, HCV and VDRL were negative .

Renal function tests were normal. Liver function tests showed elevated aminotransferases and low albumin $2.2 \mathrm{gm} / \mathrm{dl}$ and PT INR was elevated (2.8). ANA profile was negative. C-ANCA and PANCA were negative.

Rheumatoid factor and Anti CCP antibodies were negative

Echocardiography: No evidence of infective endocarditis. No regional wall motion abnormality. Good LV and RV systolic and diastolic function.

Ferritin:- $1347 \mathrm{mcg} / \mathrm{liter}$

Triglycerides: $796 \mathrm{mg} / \mathrm{dl}$

Albumin: $2.2 \mathrm{gm} / \mathrm{dl}$

LDH :- $896 \mathrm{U} / \mathrm{lit}$

LFTS: SGOT:84 U/lit.

D dimer:700ng/ml.

MRI Brain was normal. HRCT CHEST: No abnormality detected

CECT Abdomen showed hepatosplenomegaly and no lymphadenopathy

PET Scan showed Hyper metabolicsplenic lesions , FNAC was done and no abnormal cells detected and cultures were also negative .

Bone marrow biopsy: shows haemophagocytes and histiocytes.

Initially the patient was treated with anti malarial drugs and empirical antibiotics but not improved and still had high grade fever and low blood counts. All other diseases causing prolonged fevers with arthralgia ,altered sensorium were excluded and clinical criteria was fitting to Adult onset Still's disease that was complicated to Macrophage activation syndrome and secondary HLH .Patient was treated with pulse therapy methylprednisolone, cyclosporine followed by oral steroids her fever was subsided and sensorium improved and her blood counts were also improved.

\section{Discussion}

The clinical features and investigations suggestive of Macrophage activation syndrome and secondary haemophagotic lymphohistiocytosis in this patient were prolonged history of fever, anaemia, thrombocytopenia ,altered sensorium (neurological manifestations) and Hypertriglyceridemia, Serum Ferritin $>1000 \mathrm{mcg} / \mathrm{lit}$, increased LDH, coagulopathy and bone marrow biopsy showed haemophagocytes and histiocytes and after excluding all other causes of HLH and with history of prolonged fever, arthralgia, splenomegaly, neutrophil predominant leucocytosis (initially), negative 
ANA test, negative rheumatoid factor and abnormal aminotransferases and with past history of recurrent on and off episodes of fever with arthralgiasince 10 years all these features and investigations fulfilled the Yamaguchi criteria for Adult onset Still's disease and the patient was improved with pulse therapy of steroid, cyclosporine followed by oral steroids. 